\title{
Rancang Bangun Alat Uji Injektor Nozzle Spray Semi Otomatis
}

\author{
Padang Yanuar*, Ampala Khoryanton, Gio Oktariza \\ Jurusan Teknik Mesin Politeknik Negeri Semarang \\ J1. Prof. Sudharto, SH., Tembalang-Semarang 50275, Telp.+6247473417
}

*E-mail: padang.yanuar@polines.ac.id

Diterima: 16-07-2021; Direvisi: 25-07-2021; Dipublikasi: 25-08-2021

\begin{abstract}
Abstrak
Injektor merupakan salah satu komponen di mesin diesel yang berfungsi sebagai aktuator ujung sistem bahan bakar diesel dengan fungsi untuk mengabutkan solar bertekanan kedalam ruang bakar. Pengetesan injektor merupakan salah satu metode perawatan yang digunakan untuk mengetahui kondisi injektor, pengetesan injektor secara manual membutuhkan waktu yang tergolong lama dan tidak ramah lingkungan. Cara kerja injektor tester manual yaitu dengan cara memompakan tuas yang terhubung dengan pressure gauge yang menyebabkan bahan bakar mengalir ke injektor, jika tekanan sudah tercapai maka bahan bakar akan keluar dari injektor. Tujuan dari makalah ini adalah menyampaikan hasil rancang bangun alat uji injektor dengan desain yang efektif dan efisien. Metode penelitian ini meliputi identifikasi masalah, studi pustaka, serta rancang bangun alat. Hasil yang diperoleh adalah alat uji injektor mampu digunakan untuk menguji 4 injektor secara bersamaan dengan dilengkapi motor sebagai penggerak serta dilengkapi penampungan bahan bakar hasil pengujian. Kesimpulan dari penelitian ini adalah rancang bangun alat uji injektor dengan motor penggerak dapat mempersingkat waktu pengujian dan dapat melindungi lingkungan dari cemaran bahan bakar yang keluar dari alat uji.
\end{abstract}

Kata kunci: alat uji; diesel; injektor; rancang bangun

\begin{abstract}
The injector is one of the components in the diesel engine that functions as the actuator of the end of the diesel fuel system with the function of atomizing pressurized diesel into the combustion chamber. Injector testing is one of the maintenance methods used to determine the condition of the injectors, manual injector testing takes a long time and is not environmentally friendly. The way the manual injector tester works is by pumping the lever connected to the pressure gauge which causes fuel to flow into the injector, if the pressure has been reached, the fuel will come out of the injector. The purpose of this paper is to convey the results of the design of the injector test equipment with an effective and efficient design. This research method includes problem identification, literature study, and tool design. The results obtained are the injector test equipment can be used to test 4 injectors simultaneously equipped with a motor as a propulsion and equipped with a fuel storage test results. The conclusion of this study is that the design of the injector test equipment with a driving motor can shorten the testing time and can protect the environment from fuel contamination that comes out of the test equipment.
\end{abstract}

Keywords: design; diesels; test equipment; injector

\section{Pendahuluan}

Teknologi mesin pembakaran internal seperti mesin diesel banyak dipilih dalam aplikasi peralatan dengan tugas yang berat karena penghematan bahan bakar, ketangguhan, dan keandalannya [1]. Pada Gambar 1 merupakan salah satu contoh penggunaan mesin diesel pada alat berat forklift dengan merek komatsu tipe 8 ton yang banyak digunakan di industri kilang minyak [2]. Proses pembakaran pada mesin diesel tidak menggunakan percikan bunga api dari busi seperti yang digunakan pada mesin berbahan bakar bensin. Pada diesel udara dihisap dan dikompresikan sampai meningkatkan tekanan dan temperaturnya. Bahan bakar diinjeksikan langsung dengan tekanan 30-150 MPa kedalam silinder mendekati akhir langkah kompresi melalui nozzle menyebabkan bahan bakar secara spontan menyala akibat temperatur tinggi yang dicapai oleh udara didalam silinder selama proses kompresi [3] [4].

Efisiensi mesin diesel dipengaruhi oleh kesempurnaan proses pembakaran bahan bakar didalam silinder. Adapun kesempurnaan pembakaran dipengaruhi oleh beberapa faktor diantaranya adalah tekanan penyemprotan bahan bakar, 
pengkabutan udara pembakaran, kepadatan, suhu udara, perbandingan udara, kecepatan putaran mesin, suhu udara isap, suhu air pendingin dan juga dari jenis bahan bakar (suhu, viskositas, bilangan cetan, daya penguapan) [5] [6].

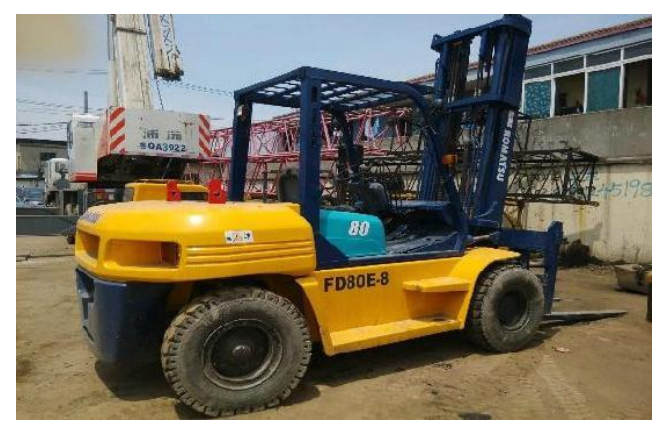

Gambar 1. Forklift komatsu 8 T [3]

Sistem injeksi berperan dalam proses pembakaran bahan bakar, pengamatan terhadap satu kinerja injektor banyak diperhatikan. Tekanan injeksi yang tinggi akan menghasilkan penetrasi yang lama dan area semprotan yang lebih besar sehingga mempercepat proses pembakaran dan mengurangi pembakaran tidak sempurna [7][8]. Berkebalikan dengan hal tersebut, injektor yang mengalami sumbatan akibat pembentukan endapan karbon menyebabkan kerugian pada efisiensi mesin dan peningkatan cemaran pada emisi gas buang, dengan demikian kebersihan injektor harus diperhatikan [9][10][11]. Pada Gambar 2 ditunjukan alat pengujian tekanan injektor secara manual, alat tersebut digunakan untuk mengetahui tekanan dan bentuk pengabutan injektor (satu kali pengujian satu injektor). Penggunaan alat uji manual ini mengandalkan kekuatan manusia sebagai sumber tenaga, selain itu pada pengujian menggunakan alat ini hanya mampu melakukan satu injektor untuk sekali uji.

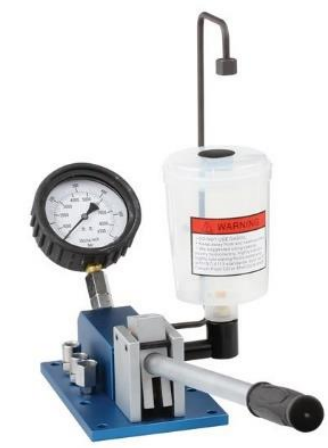

Gambar 2. Alat uji injektor [12]

Berdasarkan kajian pustaka tentang pentingnya perawatan injektor, perlu dilakukan penelitian yang membahas tentang pengembangan peralatan pengujian perawatan injektor semi automatis. Dengan membuat alat uji injektor diharapkan dapat ditemukan solusi bagaimana cara untuk menguji dan merawat injektor secara efektif. Tujuan dari penelitian ini adalah rancang bangun alat uji Injektor Nozlle Spray Semi Otomatis yang efektif dan efisien sedangkan metode yang digunakan meliputi identifikasi masalah, studi pustaka, serta rancang bangun alat.

\section{Material dan metodologi}

Perancangan merupakan kegiatan awal dalam proses pembuatan injektor tester semi otomatis, tahap perancangan tersebut dibuat keputusan-keputusan penting yang mempengaruhi kegiatan-kegiatan lain sebelum sebuah produk dibuat, proses perancangan akan menghasilkan sebuah gambar sketsa atau gambar sederhana dari produk yang akan dibuat [13] [14]. Rancang bangun pada injektor tester semi otomatis ini diawali dari penentuan desain dan kemudian dilakukan perhitungan dan simulasi menggunakan aplikasi solidworks. 
Proses pembuatan alat ini meliputi persiapan material yang akan digunakan, proses pemesinanan (fabrication), penentuan electrical dan mechanical serta assembly semua komponen. Material yang akan dipakai untuk injektor tester semi otomatis seperti tubing ASTM A214, akrilik, dan baja ASTM A36 6 (mm). Proses pembuatan alat ini dilakukan dengan menggunakan pengelasan SMAW, pengelasan dilakukan untuk pembuatan bench pada injektor dengan material ASTM A214, dilanjutkan dengan pemotongan baja ASTM A36 sebagai alas pada bench injektor tester, pengelasan juga dilakukan pada pemasangan ring stand motor listrik yang menghubungkan dengan injection pump. Dilanjutkan dengan pembengkokan tubing ASTM A269 sesuai dengan desain yang telah dibuat. Proses pembuatan alat pada injektor tester ini lebih berfokuskan pada proses assembly dikarenakan untuk komponen utama seperti injection pump, motor listrik dan lainnya merupakan material standar, sehingga pembuatan alat disini difokuskan pada pembuatan bench injektor tester. Proses selanjutnya adalah perakitan semua komponen yang sudah disiapkan dan yang terakhir adalah proses pengujian fungsi alat injektor tester.

\section{Hasil dan Pembahasan}

\subsection{Hasil Perancangan}

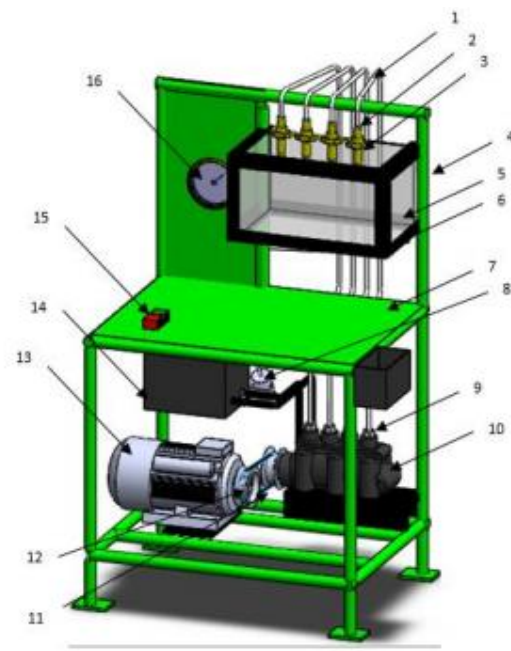

Gambar 3. Hasil Rancangan 3 Dimensi Injektor Tester Semi Otomatis

Pada Gambar 3 merupakan hasil dari desain rancang bangun injektor tester yang sudah dilengkapi dengan keterangan peralatan yang akan digunakan (disajikan pada Tabel 1), dari hasil perancangan didapatkan ukuran rangka adalah Panjang $834(\mathrm{~mm})$ x Lebar $634(\mathrm{~mm})$ x Tinggi $1427(\mathrm{~mm})$. Rancangan alat ini memiliki keunggulan dalam hal jumlah injektor yang akan diuji yaitu sejumlah 4 injektor dalam sekali uji, hal ini menjadi pembeda dengan alat uji injektor lain untuk digunakan pada penelitian yang hanya menggunakan satu injektor sekali uji [7][8][12].

Tabel 1. Keterangan nama peralatan

\begin{tabular}{clcl}
\hline No & Nama alat & No & Nama alat \\
\hline 1 & Tubing ASTM A269 & 9 & connector injection pump \\
2 & Union tubing & 10 & injection pump \\
3 & Injektor & 11 & Belt \\
4 & Tubing ASTM A214 & 12 & Pully \\
5 & Akrilik Penampungan BB & 13 & Motor Listrik \\
6 & Baja ASTM A 36 & 14 & fuel tank \\
7 & Baja ASTM A 36 & 15 & Switch on/off \\
8 & Fuel filter & 16 & Pressure Gauge \\
\hline
\end{tabular}


Padang Yanuar dkk /Jurnal Rekayasa Mesin

p-ISSN: 1411-6863, e-ISSN: 2540-7678

Vol.16|No.2|279-285|Agustus|2021

\subsection{Estimasi Perhitungan Massa Alat}

Dari data Tabel 1 dapat dilakukan perhitungan massa komponen alat menggunakan software solidworks, hasil perhitungan didapatkan dengan cara memasukkan ukuran dan nama material yang sesungguhnya pada software solidwork [15] didapatkan hasil seperti yang disajikan pada Tabel 2. Total massa komponen adalah 125,091 kg, sedangkan untuk penentuan nilai center of gravity didapatkan titik pusat massa pada bench injektor tester semi otomatis pada sumbu x,y,z berturut-turut adalah $[(369,3) ;(838,5) ;(1151,2)] \mathrm{mm}$ dari titik koordinat yang telah ditentukan. Untuk memperjelas dapat dilihat pada Gambar 4.

Tabel 2. Perhitungan Massa komponen menggunakan software Solidworks

\begin{tabular}{|c|c|c|c|c|}
\hline No & Komponen & Jumlah & material & Massa total (kg) \\
\hline & Main Body & 1 & ASTM A214 & 68,247 \\
\hline & Alas Bench & 1 & ASTM A36 & 10,91 \\
\hline & Injektor & 4 & DIN50602K1 & 3,52 \\
\hline & Injection Pump & 1 & Standart & 14,127 \\
\hline & Motor Listrik & 1 & Iec $60034-5 /$ cast iron & 7 \\
\hline & Tubing High Pressure & 4 & ASTM A269 & 1,64 \\
\hline & Kerangka Penampung Solar & 1 & ASTM A36 & 4,248 \\
\hline & Penampung Solar & 1 & Acrylic & 0,567 \\
\hline & Fuel Tank & 1 & ASTM A36 & 12,955 \\
\hline & Pully & 2 & DIN 1691 & 0,473 \\
\hline & \multirow[t]{2}{*}{ Belt } & 1 & AISI 410 & 1,404 \\
\hline & & & Total & 125,091 \\
\hline
\end{tabular}

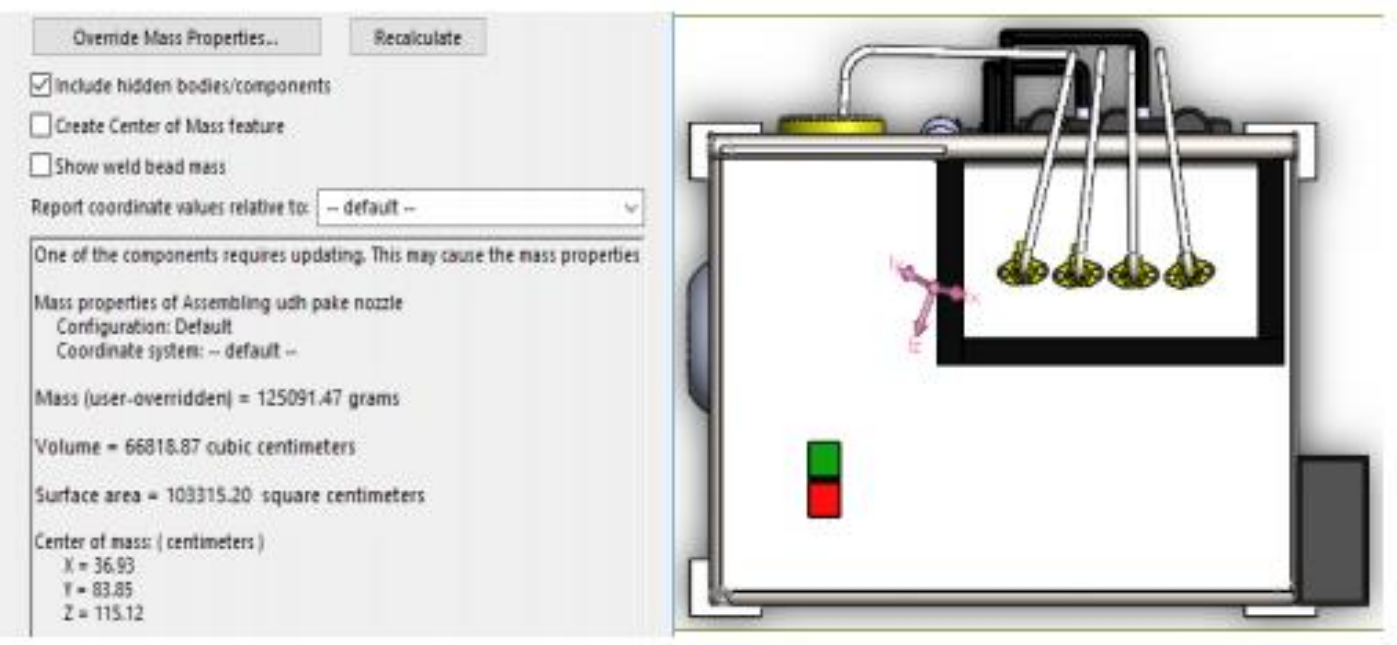

Gambar 4. Center of Mass Injector Tester Semi Otomatis

\subsection{Proses Pembuatan Alat}

Setelah proses design dilanjutkan dengan proses pembuatan alat., kegiatan awal yang dilakukan adalah pembuatan rangka utama dan tangki bahan bakar melalui proses pengelasan seperti terlihat pada Gambar 5, setelah proses ini selesai kemudian dilanjutkan dengan proses perakitan komponen alat pendukung seperti injection pump, fuel filter, motor listrik, 
tubing, injektor, akrilik penampungan, pressure gauge ,pully dan belt ke rangka utama. Hasil akhir rancang bangun Injector Tester Semi Otomatis dapat dilihat pada Gambar 6.

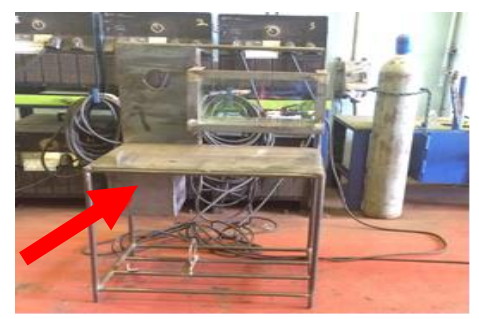

Gambar 5. Kerangka utama

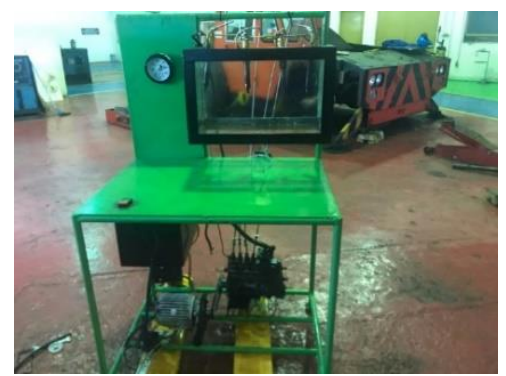

Gambar 6. Hasil Rancang Bangun Injector Tester Semi Otomatis

\subsection{Proses Pengujian Alat}

Sebagai tahap akhir dari proses ini adalah pengujian alat, mekanisme yang dilakukan adalah dengan memasang 4 buah injektor pada union tubing (komponen alat no 2 pada Tabel 1) pada pengujian ini menggunakan injektor Forklift Komatsu $8 \mathrm{~T}$. Tekan tombol on yang berarti akan mengaktifkan seluruh rangkaian kerja alat yaitu tangki bahan bakar sebagai tempat penampung bahan bakar, mengalirkan bahan bakar menuju priming pump, selanjutnya bahan bakar masuk ke fuel filter untuk menyaring bahan bakar sebelum menuju injection pump, injection pump mengalirkan bahan bakar bertekanan tinggi dengan bantuan putaran motor listrik (850 Rpm) menuju tubing high pressure, dari tubing high pressure bahan bakar menuju pressure gauge dan kemudian bahab bakar menyemprot keluar dari ujung injektor, bahan bakar yang sudah disemprotkan kemudian ditampung pada penampung bahan bakar yang kemudian kembali dialirkan menuju fuel tank agar bahan bakar dapat kembali digunakan dalam pengetesan.

Tabel 3. Hasil pengujian

\begin{tabular}{ccccccc}
\hline $\begin{array}{c}\text { No } \\
\text { Injector }\end{array}$ & $\begin{array}{c}\text { Tekanan 1 } \\
\text { (Bar) } \\
\text { alat manual }\end{array}$ & $\begin{array}{c}\text { Bentuk } \\
\text { Pengabutan }\end{array}$ & $\begin{array}{c}\text { Lama } \\
\text { Waktu } \\
\text { pengujian } \\
(\mathbf{s})\end{array}$ & $\begin{array}{c}\text { Tekanan 2 (Bar) } \\
\text { Alat semi } \\
\text { otomatis }\end{array}$ & $\begin{array}{c}\text { Lentuk } \\
\text { Pengabutan }\end{array}$ & $\begin{array}{c}\text { Waktu } \\
\text { pengujian } \\
(\mathbf{s})\end{array}$ \\
\hline 1 & 134 & Ada tetesan & 480 & 149 & Baik & \\
2 & 144,25 & Ada tetesan & 480 & 149,25 & Baik & 720 \\
3 & 124,25 & Ada tetesan & 480 & 149 & Baik & \\
4 & 134 & Ada tetesan & 480 & 149 & Baik & \\
\hline
\end{tabular}

Tabel 3 merupakan hasil perbandingan pengujian injektor menggunakan alat uji manual dan semi otomatis, yang dimaksud dari tekanan 1 adalah tekanan dimana injektor diuji menggunakan alat uji manual hasil tekanan pada 4 injektor menunjukan variasi nilai yang berbeda-beda nilai terendah pada tekanan 124,25 bar dengan pengabutan yang tidak sempurna dengan ditandai munculnya tetesan pada ujung injektor, waktu yang dibutuhkan untuk masing-masing uji adalah 
Padang Yanuar dkk /Jurnal Rekayasa Mesin p-ISSN: 1411-6863, e-ISSN: 2540-7678 Vol.16|No.2|279-285|Agustus|2021

$480 \mathrm{~s}$ Informasi dari tekanan awal dan bentuk pengkabutan digunakan sebagai langkah untuk dilakukannya perawatan pembersihan injektor, setelah proses perawatan selesai kemudian dilanjutkan dengan pengujian kembali, data tekanan 2 menunjukan injektor sesudah perawatan mengalami peningkatan tekanan dengan rata-rata 149 bar dengan bentuk pengabutan yang sempurna tanpa adanya tetesan dan waktu yang dibutuhkan untuk pengujian 4 injektor adalah $720 \mathrm{~s}$. Tekanan injektor hasil pengujian masuk kedalam keadaan injektor dinyatakan dalam kondisi dibawah dari tekanan injektor baru yang memiliki nilai antara 151-159 [2], dilihat dari selisih yang kecil dapat diartikan injektor masih dapat untuk digunakan.

\section{Kesimpulan}

Pengembangan alat uji injektor yang mampu digunakan untuk menguji 4 injektor secara bersamaan dengan dilengkapi motor sebagai penggerak serta dilengkapi penampungan bahan bakar hasil pengujian dengan desain yang dibuat seefektif mungkin yaitu dengan model closed system yang berarti bahan bakar yang keluar dari injektor hasil pengujian dapat ditampung dan dapat dipakai kembali, alat ini juga memiliki efisiensi waktu pengujian jika dibandingkan dengan alat pengujian injektor secara manual alat ini juga melindungi lingkungan sekitar karena bahan bakar hasil pengujian tidak keluar ke lingkungan dikarenankan terdapat akrilik penampungan.

\section{Ucapan terima kasih}

Penulis mengucapkan terimakasih kepada Pertamina Refinery Unit IV Cilacap atas dukungan pada penelitian ini.

\section{Referensi}

[1] C.H. Achebe, B.M.O. Ogunedo, J.L. Chukwuneke, N.B. Anosike. Analysis of diesel engine injector nozzle spray characteristics fueled with residual fuel oil. Journal Heliyon. 2020 Agustus; 6: p. 1. https://doi.org/10.1016/j.heliyon.2020.e04637

[2] Komatsu., Specifications Pneumatic Tire Lift Trucks 8,000 - 11,000 lbs. Capacity KOMATSU FORKLIFT. Komatsu Forklift U.S.A; Covington: 2004.

[3] Breeze, P. (2018). Diesel Engines. Piston Engine-Based Power Plants, Elsevier Ltd, 2018; p.47-57. doi:10.1016/b9780-12-812904-3.00005-7

[4] Kamimoto, T., \& Kobayashi, H. Combustion processes in diesel engines. Progress in Energy and Combustion Science. 1991; 17(2): p. 163-189. doi:10.1016/0360-1285(91)90019-j

[5] Indartono, Murni. Pengaruh Pemakaian Alat Pemanas Bahan Bakar Terhadap Pemakaian Bahan Bakar Dan Emisi Gas Buang Motor Diesel Mitsubishi Model 4D34-2A17. Jurnal Traksi. 2016; 16(2): p.66-73

[6] Shi, Z., Lee, C., Wu, H., Li, H., Wu, Y., Zhang, L Liu, F. Effect of injection pressure on the impinging spray and ignition characteristics of the heavy-duty diesel engine under low-temperature conditions. Applied Energy, 2020 Januari; 262: p.1. doi: 10.1016/j.apenergy. 2020.114552

[7] Ghurri, A., Kim, J.-D., Kim, H. G., Jung, J.-Y., \& Song, K.-K. The effect of injection pressure and fuel viscosity on the spray characteristics of biodiesel blends injected into an atmospheric chamber. Journal of Mechanical Science and Technology;2012: 26(9), 2941-2947. doi:10.1007/s12206-012-0703-1

[8] Rusly A, Le MK, Kook S. Effect of injection pressure on transient behaviour of wallinteracting jet flame base in an automotive-size diesel engine. SAE Internasional Journal of Fuel and Lubrication. 2013 November; 6 (3): p.615-626. 
[9] D’Amico, M., Zampilli, M., Laranci, P., D’Alessandro, B., Bidini, G., \& Fantozzi, F. Measuring Injectors Fouling in Internal Combustion Engines through Imaging. Energy Procedia. 2015; 82: p. 9-16. doi:10.1016/j.egypro.2015.11.873

[10] Li H., Lea-Langton A., Biller P, Andrews G. E. Hadavi S., Charlton A. and Richards P., Effect of Multifunctional Fuel Additive Package on fuel injector deposit, combustion and emissions using pure rape seed oil for a DI diesel,

SAE International Journal of Fuels and Lubricants. 2010 Maret; 2: pp. 54-65. doi: 10.4271/2009-012642.

[11] Pranoto,A., Purwanto, A. Analisa Kerusakan Dan Model Perawatan Injektor Pada Sistem Injeksi Bahan Bakar Elektronik. Jurnal Teknologi. 2014 Desember; 7 (2): p. 175-180.

[12] Toledo - Diesel Injector Tools. https://tridon.com.au/products/Toledo/21/327626/fuel/467519/diesel-injectortools/446643/307350. Australia, 2020. [Diakses pada tanggal 25 Juli 2021].

[13] Dharmawan, H. Pengantar Perancangan Teknik. Jakarta: Direktorat Jendral Pendidikan Tinggi; 2000.

[14] Richard G. Budynas, J. Keith Nisbet. Shigley’s Mechanical Engineering Design, Ninth Edition. The McGraw-Hill Companies, Inc., 1221 Avenue of the Americas, New York; 2011.

[15] Company, D. S. 3. E. Solidworks Simulation Suite Drive Innovation With 3D Enginners Solution. s.l.:Dassault Systems Solidworks Corporation; 2017. 